\title{
Sociobiology
}

RESEARCH ARTICLE - ANTS

\section{Insecticidal Activity of the Soil in the Rhizosphere of Viburnum odoratissimum against Solenopsis invicta (Hymenoptera: Formicidae)}

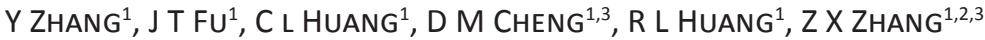 \\ 1 - South China Agricultural University, Key Laboratory of Natural Pesticide \& Chemical Biology, Ministry of Education, Guangzhou, China \\ 2 - State Key Laboratory for Conservation and Utilization of Subtropical Agro-Bioresources, Guangzhou, China \\ 3 - Zhongkai University of Agriculture and Engineering, Guangzhou, China
}

\author{
Article History \\ Edited by \\ Evandro Nascimento Silva, UEFS, Brazil \\ Received 10 May 2016 \\ Initial Acceptance 08 January 2017 \\ Final Acceptance 27 February 2017 \\ Publication date 29 May 2017

\section{Keywords} \\ Mortality, repellency, soil, leaf, methyl \\ salicylate. \\ Corresponding author \\ ZX Zhang \\ South China Agricultural University \\ Key Laboratory of Natural Pesticide \& \\ Chemical Biology \\ Ministry of Education, Guangzhou \\ 510642, China. \\ E-Mail: zdsys@scau.edu.cn
}

\begin{abstract}
Methyl salicylate produced by Viburnum odoratissimum is known to exert lethal or sublethal effects on insects. Replacing conventional pesticides with insecticidal plants is necessary for environmental protection. We evaluated the behavioral and toxicological responses of the red imported fire ant (RIFA Solenopsis invicta, Buren) (Hymenoptera: Formicidae) at different soil depths in the rhizosphere of $V$. odoratissimum. Results of insecticidal activity bioassays indicated that the mortality for minor and major ants in soil at depths of 0-10 $\mathrm{cm}$ at days 11 and 12 both ranged from $68.75 \%$ to $100.00 \%$, with repellency rates of $83.54 \%-100.00 \%$ and $85.31 \%-100.00 \%$, respectively. In behavioral ability tests, $85.45 \%-100.00 \%$ of minor ants and $86.74 \%-94.85 \%$ of major ants lost their ability to grasp after nine days, with crawling rates at only $0.00 \%$ $29.25 \%$ and $0.00 \%-55.77 \%$, respectively. Therefore, we conclude from the result that the soil under $V$. odoratissimum at depths of 0-10 cm exhibited excellent insecticidal effect in controlling RIFA.
\end{abstract}

\section{Introduction}

The red imported fire ant (RIFA), Solenopsis invicta Buren, is an important invasive species native to South America. RIFAs are more aggressive than other ant species and have been identified to disrupt the balance of natural ecosystems (Porter, 1990). RIFAs also cause considerable harm in infested urban and agricultural areas. In the city, RIFA colonies are commonly found in gardens, lawns, parks, schoolyards, and golf courses. These insects are a threat to people's health because of their sting, which may cause inflammation, vesicles, sterile pustules, allergic phenomena, and even anaphylactic shock (Haddad et al., 2015). The venom of the RIFA is composed of various alkaloids, which can negatively affect the cardiovascular and central nervous system of vertebrates (Howell et al., 2005). The RIFA has spread over a number of countries and regions; it was detected in Taiwan in 2003 (Zhang et al., 2007) and mainland China in 2004 (Zhang et al., 2013). At present, the species can be found in South China and occupies an area of at least $71 \mathrm{~km}^{2}$ (Lai et al., 2015).

RIFAs are usually controlled by applying traditional insecticides, such as richlorphon or clofenotane; both are harmful to humans and the environment. Thus, the search for natural, safe and non-polluting methods began to attract considerable attention, and many efforts have focused on exploring biological control (Appel et al., 2004; Vogt et al., 2002).

Methyl salicylate is an organic ester that is naturally produced by Viburnum odoratissimum (Wei et al., 2013). It is a volatile oil with a characteristic wintergreen odour and taste, and is used as a flavouring agent and as a topical counterirritant for muscle pain (Liu et al., 2013). The compound was first 
registered as a pesticide in 1972 for use as an animal repellent in impregnated twist tabs hung on plants to repel dogs and cats from flower gardens. In 1996, the Hygienic standards for uses of food additives approved methyl salicylate as an insect repellent to be used as a constituent of food and feed packaging material to repel insects in stored commodities.

In this study, methyl salicylate from $V$. odoratissimum leaves and soil were analyzed by using high-performance liquid chromatography (HPLC), and soil toxicity was determined to evaluate the effectiveness of the soil in the rhizosphere of $V$. odoratissimum in controlling the RIFAs.

\section{Materials and methods}

\section{Plant}

V. odoratissimum used in the study was planted in the Insecticidal Botanical Garden at South China Agricultural University. The height of the trees was approximately $2 \mathrm{~m}$, and the basal stem diameter was approximately $3 \mathrm{~cm}$. Grasses and other small plants within $5 \mathrm{~m}$ of the basal stem were cleared artificially within 30 days. All plants were cleared artificially within 30 days in a CK field $\left(20 \mathrm{~m}^{2}\right)$, which is located approximately $30 \mathrm{~m}$ from the field of $V$. odoratissimum.

\section{Chemicals}

Methyl salicylate was purchased from Jingchun Chemical Reagent Co., Ltd., Shanghai, China. HPLC-grade acetonitrile and methanol, as well as analytically pure phosphoric acid, were purchased from Guangzhou Chemical Reagent Factory.

\section{Insects}

Adult workers of $S$. invicta colonies were obtained directly from nests in South China Agricultural University. Workers were reared in plastic cases coated with Teflon emulsion on the top, in which a test tube $(25 \mathrm{~mm} \times 200$ $\mathrm{mm}$ ) filled with water and plugged with cotton was used to provide water. A Petri dish $(8.5 \mathrm{~cm} \times 1.5 \mathrm{~cm})$ that contained individuals of Tenebrio molitor was placed in containers for the food source. Individuals of $T$. molitor was purchased from the insect/fish market in Guangzhou, fed with wheat bran, and kept in a dry indoor environment at $25 \pm 2{ }^{\circ} \mathrm{C}$ until use. Small worker ants were approximately $3 \mathrm{~mm}$ in length, whereas large worker ants applied in the experiment were approximately $6 \mathrm{~mm}$ in length (Cheng et al., 2008; Zhou et al., 2013; Zhang et al., 2013; Tang et al., 2013).

\section{Collection of soil and leaf samples}

The soil samples were collected at five points/tree, $20 \mathrm{~cm}$ from the basal stem, at depths of 0-5, 5-10, 10-15 and $15-20 \mathrm{~cm}$. Soil samples from the same depth were combined and ground, and then sifted with a 40 mesh sieve. Each sample was replicated thrice, and a tree was used in each replication. Soil weight/replicate was set at $>500 \mathrm{~g}$. The soil samples were collected randomly at five points at the same depth. For the leaf samples, young and old green leaves, as well as yellow leaves, were picked from each tree. Leaf weight/replicate was obtained at $>200$ g. Half of the leaves and soil samples were placed in a dryer to dry for $12 \mathrm{~h}$ at $100^{\circ} \mathrm{C}$. The collected leaf and soil samples were stored in the refrigerator at $-4{ }^{\circ} \mathrm{C}$ for analysis.

\section{HPLC analysis}

Graded soil (20 g) or mashed leaves (10 g) were mixed with $100 \mathrm{~mL}$ methanol in a beaker $(500 \mathrm{~mL})$ and then subjected to ultrasonic extraction for $30 \mathrm{~min}$. This procedure was replicated thrice. The extract solutions were combined, and the soil or leaves were removed through filtration. Methyl salicylate contents in the extract solution were determined by HPLC.

HPLC was performed with an Agilent TC-C18 column $(250 \mathrm{~mm} \times 4.6 \mathrm{~mm}, 5 \mu \mathrm{m})$ by using a mobile phase of acetonitrile $-0.01 \%$ phosphoric acid solution (40:60), with a flow rate of $1.0 \mathrm{~mL} / \mathrm{min}$, column temperature of $30^{\circ} \mathrm{C}$, detection wavelength of $302 \mathrm{~nm}$, and injection volume of $10 \mu \mathrm{L}$.

\section{Toxicity bioassay}

Toxicity bioassay was determined by using the method proposed by Zhang et al. (2013) with some modifications. Graded soil (10 g) was placed in a $200 \mathrm{~mL}$ beaker, with the vertical wall inside each glass coated with Fluon emulsion, and allowed to dry for $24 \mathrm{~h}$ to prevent the ants from escaping. Twenty individuals of each minor and major workers were laid at the bottom of a Bunsen beaker. Mortalities, walking rate, and grasping rate were observed after $5 \mathrm{~h}, 1$ day, and daily thereafter until the 12th day after treatment. The treatments were replicated thrice. The ants were kept in the laboratory at $25 \pm 2{ }^{\circ} \mathrm{C}$ and relative humidity of $80 \%$.

The mortality statistics were determined as follows: Mortality was assessed after $5 \mathrm{~h}, 1$ day, and daily thereafter until the 11th day after testing with different soils. All treatments were replicated three times. The following formula was adopted:

Mortality $=$ (number of dead ants / number of total ants) $\times 100 \%$

Corrected mortality $=($ the mortality of treatment group - the mortality of control group) / ( 1 - the mortality of control group) $\times 100 \%$

The determination of repellency rate statistics is given as follows: The rationale for the bioassay is that the ants will always exhibit digging behavior whenever an adequate digging substrate, such as soil, is available. However, the ants do not dig or dig less when the substrate contains a repellent. Therefore, repellency was defined as suppression of ant digging behavior. Soil samples $(20 \mathrm{~g})$ were placed at the bottom of a $500 \mathrm{~mL}$ beaker with a vertical wall inside each glass coated with Fluon emulsion. Then, $20 \mathrm{~g}$ of control 
soil covered the upper part of the beaker, and 10 individuals of each minor and major workers were selected and placed in a beaker. In the experiment, four treatment groups and one control group were adopted. Each treatment was replicated thrice. We found that the ants preferred to inhabit the soil without repellent over the soil with repellent. The following equation was used to determine the repellency:

Repellency rate $=$ (number of ants in the control group - number of ants in the treatment group) / number of ants in the control group $\times 100$.

Behavioral observation on the ants' walking ability was conducted as follows: Observations on the walking ability of the workers were recorded after $5 \mathrm{~h}, 1$ day, and daily thereafter until the $12^{\text {th }}$ day after testing. Afterward, the workers were placed on a piece of A4 paper. The workers were observed to possess walking ability when they walked continuously for $10 \mathrm{~cm}$ without falling. Walking rate was obtained using the following formula:

Walking rate $=$ (number of workers possessing walking ability/number of workers per replicate) $\times 100$.

Behavioral observation on the grasping ability of ants was conducted as follows: The grasping ability of the workers was recorded after $5 \mathrm{~h}, 1$ day, and daily thereafter until the 12th day after testing. The workers were placed on an A4 paper, which was gently rotated $180^{\circ}$ after $10 \mathrm{~s}$. The workers that did not fall from the A4 paper were considered to possess grasping ability. We used the following formula:

Grasping rate $=$ (number of workers possessing grasping ability / number of workers per replicate) $\times 100$.

\section{Statistical analysis}

The mortality and repellency rates were analyzed and transformed to arcsine square root values for ANOVA, followed by Duncan's multiple range test. All data were expressed as means \pm standard error. Statistical analyses were carried out using SPSS 13.0 (SPSS Inc., Chicago). Differences between the values were considered significant when $\mathrm{P}<0.05$.

\section{Results}

\section{Methyl salicylate content in the soil and leaf}

A methyl salicylate standard was quantified with an external standard curve between 0.01 and $5 \mathrm{mg} \mathrm{L}^{-1}$ (y = $36289 x, R^{2}=0.9991$ ). Methyl salicylate content in fresh soil ranged from 0.13 to $4.88 \mathrm{mg} / \mathrm{kg}$ and 0.16 to $5.97 \mathrm{mg} / \mathrm{kg}$ in dry soil; a significant difference in contents was observed among depths of $0-5,5-10,10-15$, and $15-20 \mathrm{~cm}(\mathrm{~F}=28.36, \mathrm{P}<$ $0.01)$. Methyl salicylate content $(4.88 \mathrm{mg} / \mathrm{kg})$ in the soil at depths of $0-5 \mathrm{~cm}$ was significantly higher than at other depths $(\mathrm{F}=14.56, \mathrm{P}<0.01)$. The methyl salicylate contents in the fresh and dry soil showed little difference in every depth (Fig 1). The methyl salicylate contents in the fresh leaves were $133.3,150.8$ and $106.3 \mathrm{mg} / \mathrm{kg}$, whereas those in the dry leaves were $486.6,401.2$, and $193.9 \mathrm{mg} / \mathrm{kg}$. The methyl salicylate contents in the fresh yellow leaves $(106.3 \mathrm{mg} / \mathrm{kg})$ and in the dry yellow leaves $(193.9 \mathrm{mg} / \mathrm{kg}$ ) were significantly lower than

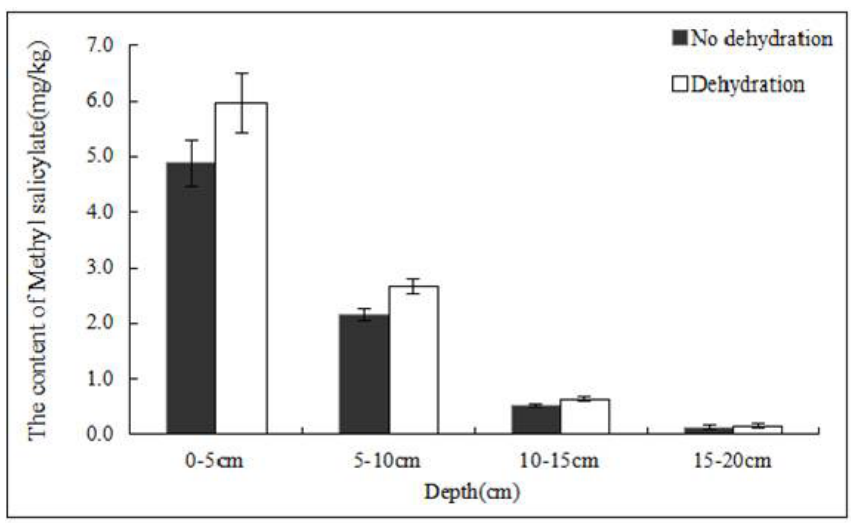

Fig 1. The content of methyl salicylate in soil in different depth.

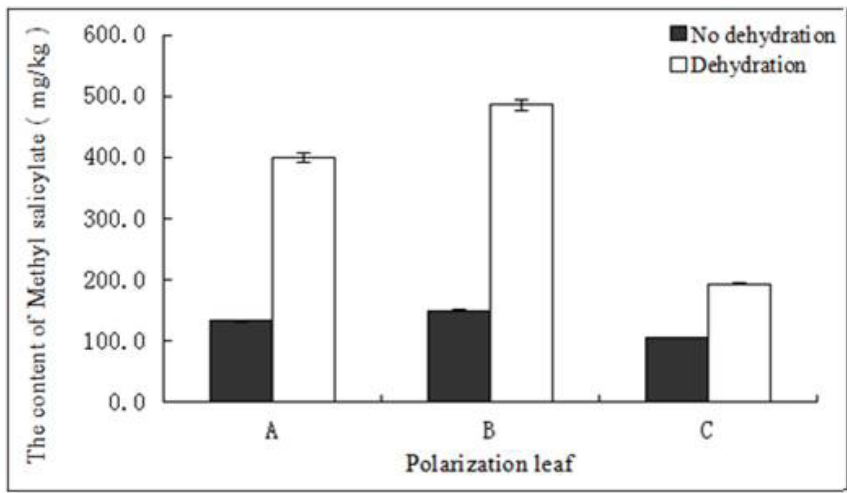

Fig 2. The content of methyl salicylate in $V$. odoratissimum leaves ( $\mathrm{A}=$ younger green leaves $\mathrm{B}=$ older green leaves $\mathrm{C}=$ yellow leaves).

those of others $(\mathrm{F}=8.41, \mathrm{P}<0.05)($ Fig 2$)$.

Insecticidal toxicity

The major ants were erradicated completely with the soil at $0-5 \mathrm{~cm}$, whereas $30.75 \%$ were killed with the soil at $15-20 \mathrm{~cm}$ depth after 12 days. This finding indicates that the soil exerted toxicity against RIFA (Fig 4). For the minor ants (Fig 3), the soil at $0-5 \mathrm{~cm}$ depth required 11 days to achieve complete minor ant death. Soil samples at 15-20 cm depth

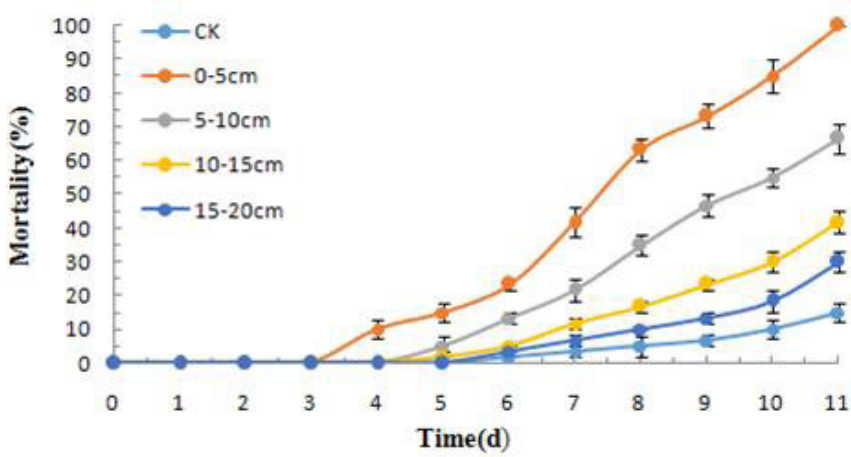

Fig 3. Mortality of minor red imported fire ants after open exposure to soil in different depth under $V$. odoratissimum. Each data point represents mean $\pm \mathrm{SE}$ of three replicate beakers each containing 20 ants. 
caused $34.75 \%$ minor ant death. We also found that in all the treatments, no ants died on the first three days, but the mortality of both minor and major workers increased with exposure time ranging from 3-11 days. Mortality of the major and minor ants almost overlapped as the exposure interval was prolonged. No significant difference $(\mathrm{F}=1.58, \mathrm{P}>0.05)$ in the mortalities between minor and major workers was found.

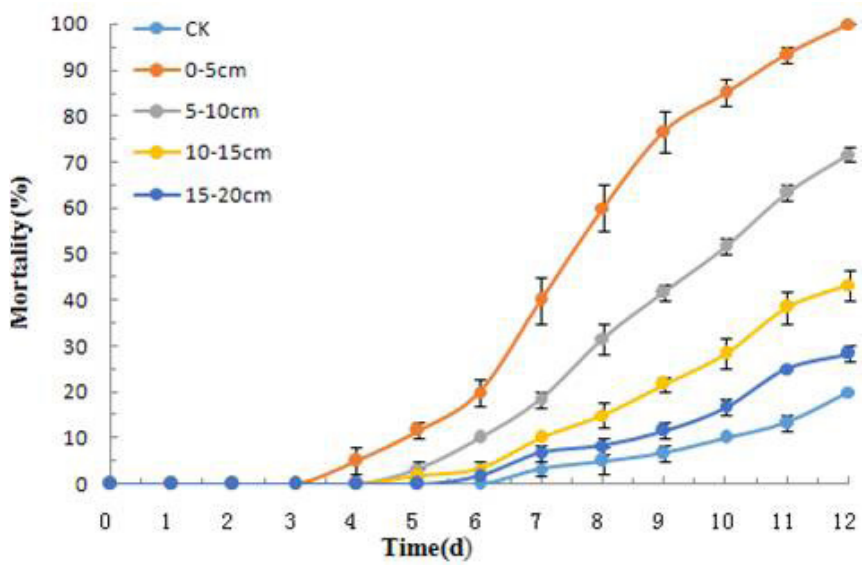

Fig 4. Mortality of major red imported tire ants after open exposure to soil in different depth under $V$. odoratissimum. Each data point represents mean \pm SE of three replicate beakers each containing 20 ants.

\section{Repellent activity bioassay}

When the major ants were placed in a beaker with soil samples at $0-5,5-10,10-15$, and $15-20 \mathrm{~cm}$ depths, the repellency against major ants reached $100.00 \%(0-5 \mathrm{~cm})$, $86.32 \%(5-10 \mathrm{~cm}), 55.56 \%(10-15 \mathrm{~cm})$, and $35.31 \%(15-20$ $\mathrm{cm}$ ) after 10 days (Fig 6). At the 9th day of treatment, the repellency against the minor ants was $100 \%, 82.72 \%, 41.29 \%$, and $29.54 \%$ (Fig 5). Both soils caused significant repellency against the major and minor ants.

\section{Walking ability bioassay}

We calculated walking abilities in accordance with Figs 7 and 8. Among the major ants, $100.00 \%(0-5 \mathrm{~cm}), 78.75 \%$ $(5-10 \mathrm{~cm}), 48.75 \%(10-15 \mathrm{~cm})$, and $30.00 \%(15-20 \mathrm{~cm})$ lost

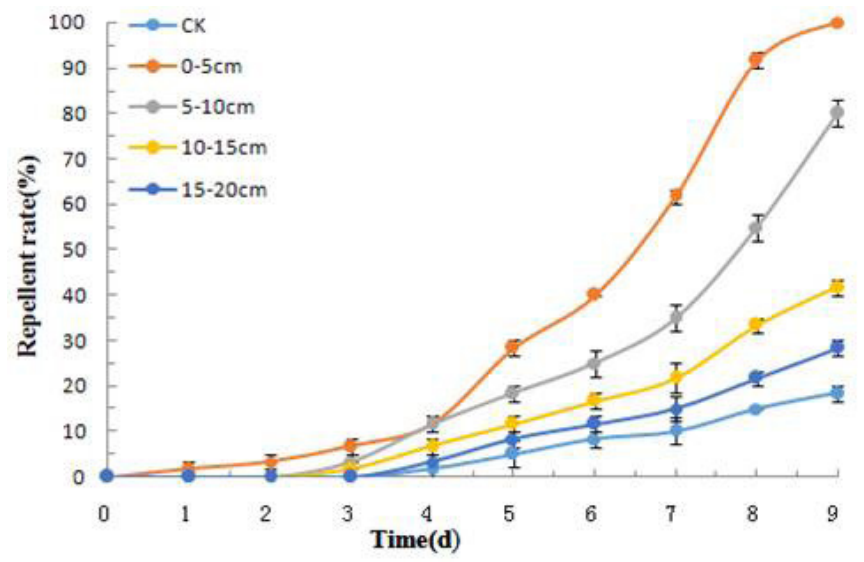

Fig 5. Repellent rate of minor ants after open exposure to soil under $V$. odoratissimum. Each data point represents mean \pm SE of three replicate beakers each containing 20 ants.

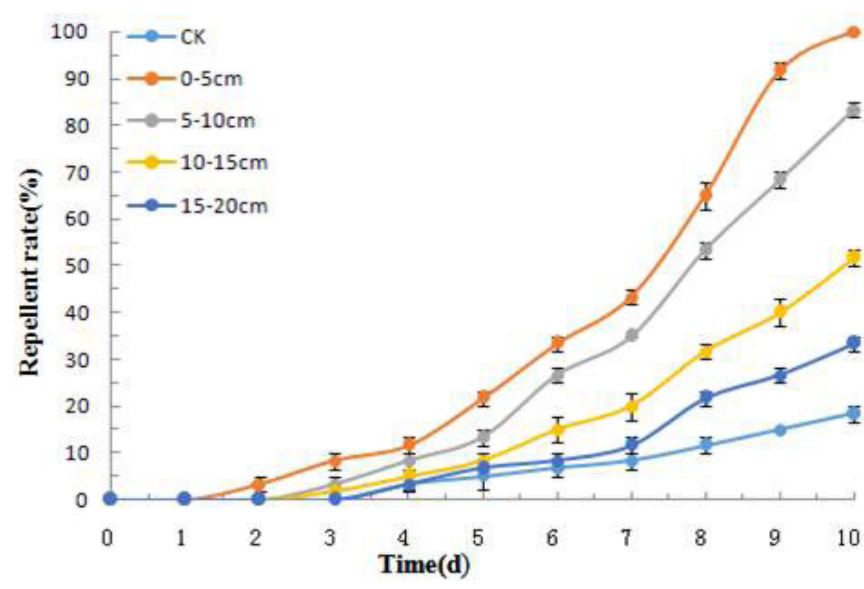

Fig 6. Repellent rate of major ants after open exposure to soil under $V$. odoratissimum. Each data point represents mean $\pm \mathrm{SE}$ of three replicate beakers each containing 20 ants.

the ability to walk after 12 days. Meanwhile, the values were $100.00 \%(0-5 \mathrm{~cm}), 85.72 \%(5-10 \mathrm{~cm}), 41.35 \%(10-15 \mathrm{~cm})$, and $27.23 \%(15-20 \mathrm{~cm})$ for the minor ants. All the major and minor ants lost walking abilities at the treated soil depths of $0-5 \mathrm{~cm}$ (Figs 7-8), which was significantly higher than the others $(\mathrm{F}=11.26, \mathrm{P}<0.01)$.

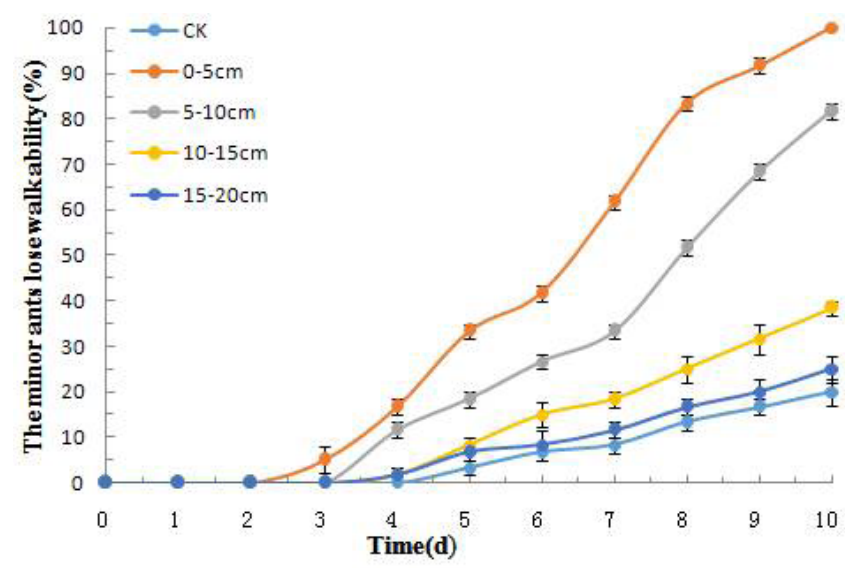

Fig 7. The rate of minor ants which lose walk ability after open exposure to soil under $V$. odoratissimum. Each data point represents mean $\pm \mathrm{SE}$ of three replicate beakers each containing 20 ants.

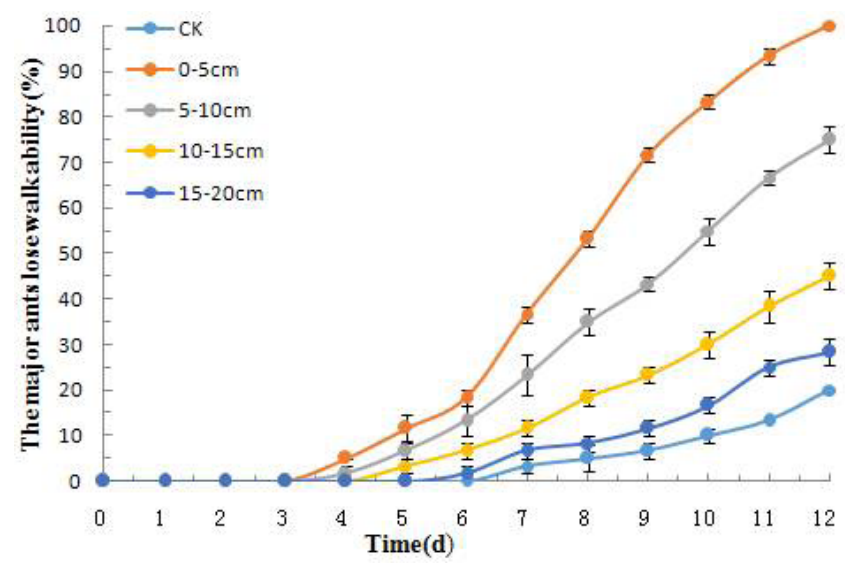

Fig 8. The rate of major ants which lose walk ability after open exposure to soil under $V$. odoratissimum. Each data point represents mean \pm SE of three replicate beakers each containing 20 ants. 
Grasping ability bioassay

The soil in the rhizosphere of $V$. odoratissimum indicated a considerable grasping suppression (Figs 9-10). Among the major ants, $95.85 \%(0-5 \mathrm{~cm}), 70.75 \%(5-10 \mathrm{~cm}), 39.64 \%(10-$ $5 \mathrm{~cm})$, and $26.74 \%(15-20 \mathrm{~cm})$ lost the ability to grasp after nine days. Meanwhile, when the minor ants were subjected to the test sequentially, the values were $100 \%(0-5 \mathrm{~cm}), 84.00 \%(5-10 \mathrm{~cm})$, $38.29 \%(10-15 \mathrm{~cm})$, and $26.45 \%(15-20 \mathrm{~cm})$. However, almost none of the ants lost grasping ability on the first three days.

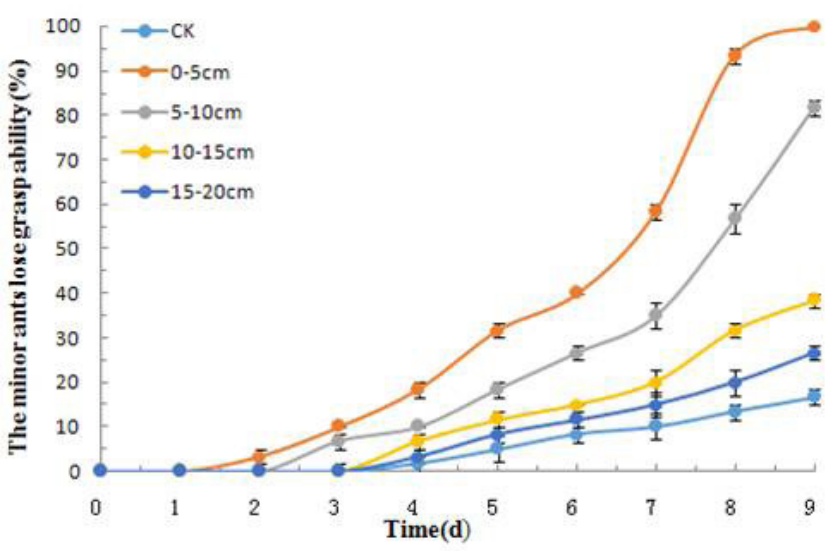

Fig 9. The rate of minor ants which lose grasp ability after open exposure to soil under $V$. odoratissimum. Each data point represents mean \pm SE of three replicate beakers each containing 20 ants.

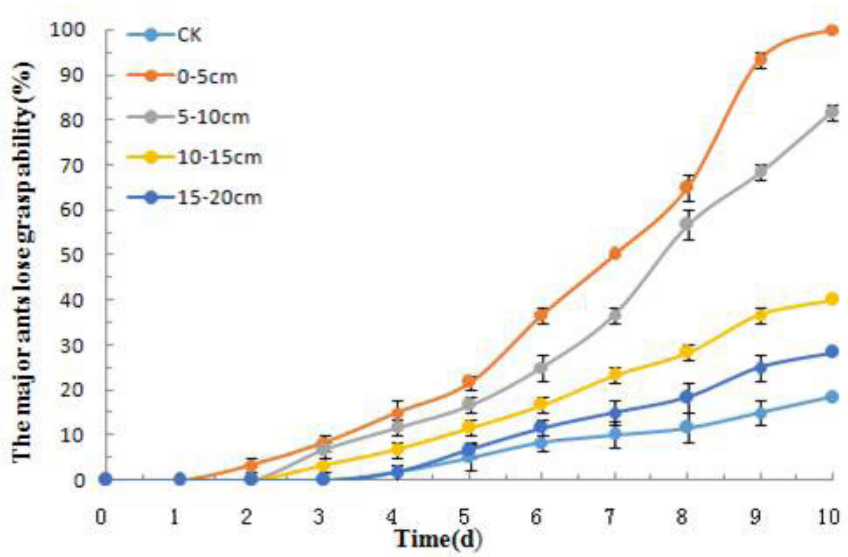

Fig 10. The rate of major ants which lose grasp ability after open exposure to soil under $V$. odoratissimum. Each data point represents mean \pm SE of three replicate beakers each containing 20 ants.

\section{Discussion}

\section{Methyl salicylate content in the leaves and soil}

The leaf and soil both contain a certain amount of methyl salicylate, and the content in the fresh and dry leaves increased initially and then decreased. This result was achieved potentially because the leaf samples were in different growing stages. Hence, the methyl salicylate in plants may serve different functions in different growth stages. However, methyl salicylate was also obtained in the soil under trees. This finding may have been achieved because of fallen leaves. $V$. odoratissimum leaves drop across all four seasons, and numerous fallen leaves cover the ground every year. Methyl salicylate could be introduced into the soil in the natural decomposition process of fallen leaves. Therefore, the chemicals can be relatively stable in the soil. This investigation also revealed that soil at different depths had different toxicities and repellent activity against $S$. invicta workers. In this study, the soil at 0-5 cm depth, which contained higher methyl salicylate levels than other samples, showed more effective insecticidal and repellent activities against RIFA than the soil at other depths. The difference in mortality values may be attributed to the content of methyl salicylate.

\section{Insecticidal and repellent activity}

This study also showed that the soil in the rhizosphere of $V$. odoratissimum containing the methyl salicylate compounds showed effective insecticidal and repellent activity against RIFA. As a fumigant, methyl salicylate is potent against many arthropods, such as mosquitoes and mites (Delaplane et al., 1992). The importance of toxic and repellent influence of the soil may provide good practical significance if such effects can also be observed when applied to urban greening.

The use of chemicals from natural products in insect pest management is generally considered a safer alternative to using synthetic contact insecticides. Some components in plants have long been known as insect repellents. For example, camphor has been used as a repellent against many insect species (Abivardi et al., 1984). Eucalyptol has also been found repel various insects, such as American cockroaches (Periplaneta americana Linn.) (Maugh et al., 1982), mosquitoes (Aedes aegypti), and Colorado potato beetles (Leptinotarsa decemlineata Say) (Scheaper et al., 1984). Repellency of some natural products has been tested against the RIFAs, such as mint oil and water suspensions of pine needle (Chenet et al., 2008). However, the use of the plant itself to control pests was rarely reported. $V$. odoratissimum is an important garden landscape plant. Given its resilience, the plant has also been applied in forest fire prevention and urban greening. Based on its long history of topical application by humans, $V$. odoratissimum is considered safe for humans and other non-target organisms in its use in many scenarios for fire ant prevention. The dose-response relationships reported in this study provide a foundation for future investigations of $V$. odoratissimum as toxicant and repellent plant against adult RIFAs. The potential use of these selective and fully biodegradable materials in the management of invasive insects is promising. However, the success of a fire ant toxic and repellent plant depends heavily on its ecosystem. Therefore, additional knowledge is needed to use $V$. odoratissimum successfully.

\section{Acknwledgement}

This work was supported by Natural Science Foundation of Guangdong Province (2016A030313387), and Guangdong Provincial Science and Technology Program (2014A020208114). 


\section{Reference}

Abivardi, C. \& Benz G. (1984). New observations on camphorsan old insect repellents as a relatively safe candidate fumigant against nine insect species. Mitteilungen der Schweizerischen Entomologischen Gesellschaft., 57: 179-187.

Alonso, C. (2014). Use of medicinal fauna in Mexican traditional medicine. Journal of Ethnopharmacology, 152: 53-70.

Appel, A.G., Gehret, M.J. \& Tanley M.J. (2004). Repellency and toxicity of mint oil granules to red imported fire ants (Hymenoptera: Formicidae). Journal of Economic Entomology, 97: 575-580.

Ascunce, M.S., Yang, C.C. \& Oakey, J. (2011). Global invasion history of the fire ant, Solenopsis invicta. Science, 331: 1066-1068.

Chang, S.T., Chen, P.F. \& Chang, S.C. (2001). Antibacterial activity of leaf essential oils and their constituents from Cinnamomum osmophloeum. Journal of Ethnopharmacology, 77: 123-127.

Chen, J. (2009). Repellency of an Over-the-Counter Essential Oil Product in China against workers of Red Imported Fire Ants. Journal of Agricultural and Food Chemistry, 57: 618-622.

Chen, J., Cantrell, C.L., Duke, S.O. \& Allen, M.L. (2008). Repellency of callicarpenal and intermedeol against workers of imported fire ants. Journal of Economic Entomology, 101: 265-271.

Delaplane, K.S. (1992). Controlling tracheal mites (Acari: Tarsonemidae) in colonies of honey bees (Hymenoptera: Apidae) with vegetable oil and menthol. Journal of Economic Entomology, 85: 2118-2124.

Haddad, J., Vidal, L. \& Carlos, E. (2015). Anaphylaxis caused by stings from the Solenopsis invicta, lava-pesant or red imported fire ant. Anais Brasileiros de Dermatologia, 90(3): 22-25.

Kim, S.I., Yoon, J.S., Jung, J.W., Hong, K.B., Ahn, Y.J. \& Kwon, H.W. (2010). Toxicity and repellency of origanum essential oil and its components against Tribolium castaneum (Coleoptera: Tenebrionidae) adults. Journal of Asia-Pacific Entomology, 13: 369-373.

Lai, L.C., Hua, K.H. \& Wu, W.J. (2015). Intraspecific and interspecific aggressive interactions between two species of fire ants, Solenopsis geminata and S. invicta (Hymenoptera: Formicidae), in Taiwan. Journal of Asia-Pacific Entomology, 18: 93-98.

Lima, J.K.A., Albuquerque, E.L.D. \& Santos, A.C.C. (2013). Biotoxicity of some plant essential oils against the termite Nasutitermes corniger (Isoptera: Termitidae). Industrial Crops and Products, 47: 246-251.

Liu, J., Zhou, W.B., Cong, Y.W. \& Liu, P. (2013). Chemistry and biological activities of Viburnum odoratissimum. Acta Pharmaceutica Sinica, 48: 325-332.
Ma, J.Z., Yang, X.W. \& Zhang, J.J. (2014). Sterols and Terpenoids from Viburnum odoratissimum. Natural Products and Bioprospecting, 4: 175-180.

Maugh, T.H. (1982). To attract or repel, that is the question. Science, 2: 218-278.

Nattrass, R. \& Vanderwoude, C. (2001). A preliminary investigation of the ecological effects of red imported fire ants (Solenopsis invicta) in Brisbane. Ecological Management and Restoration, 23: 220-222.

Novelino, A.M.S., Daemon, E. \& Soares, G.L.G. (1992). Evaluation of repellent activity of thymol, menthol, methyl salicylate and salicylic acid on Boophilus microplus larvae. Arquivo Braileiro de Medicina Veterinaria e Zootecnia, 59: 700-704.

Porter, S.D. \& Savignano, D.A. (1990). Invasion of polygyne fire ants decimates native ants and disrupts arthropod community. Ecology, 71: 2095-2106.

Rockhold, R.W. (2005). Cardiodepressant and neurologic actions of Solenopsis invicta (imported fire ant) venom alkaloids. Annals of Allergy and Asthma Immunology, 94: 380-386.

Saleem, M., Nazli, R., Afza, N., Sami, A. \& Ali, M.S. (2004). Biological significance of essential oil of Zataria multiflora Boiss. Natural Products Research, 18: 493-497.

Scheaper, W.R. (1984). Components of oil of tansy (Tanacetum vulgare) that repel Colorado potato beetles (Leptinotarsa decemlineata). Journal of Natural Products., 47: 964-969.

Wang, K., Tang, L. \& Zhang, N. (2014). Repellent and fumigant activities of Eucalyptus globulus and Artemisia carvifolia essential oils against Solenopsis invicta. Bulletin of Insectology, 67: 207-211.

Wei, J.F., Yin, Z.H. \& Kang, W.Y. (2013). Volatiles in flowers of Viburnum odoratissimum. Chemistry of Natural Compounds, 49: 154-155.

Werdin, J.O., Gutierrez, M.M., Murray, P. \& Ferrero, A.A. (2011). Composition and biological activity of essential oils from Labiatae against Nezara viridula (Hemiptera: Pentatomidae) soybean pest. Pest Management Science, 67: 948-955.

Zhang, R.Y., Li, N. \& Porter, S.D. (2007). An overview of the Red Imported Fire Ant (Hymenoptera: Formicidae) in Mainland China. Florida Entomologist, 90: 723-731.

Zhang, Z.X., Zhou, Y. \& Cheng, D.M. (2013). Effects of hematoporphyrin monomethyl ether (HMME) on Worker Behavior of red imported fire ant, Solenopsis invcita. Sociobiology, 60: 169-173. 